\title{
Efektivitas Prenatal Yoga terhadap Pengurangan Keluhan Fisik pada Ibu Hamil Trimester III
}

\author{
Rafika \\ Jurusan Kebidanan, Politeknik Kesehatan Kemenkes Palu, Indonesia \\ Email: vk_mik07@yahoo.com
}

\begin{abstract}
The Eeffectiveness of Prenatal Yoga to Reduce Physical Discomfort in Third Trimester of Pregnancy. During pregnancy, pregnant women experience physical and psychological changes that can lead to discomfort. One of pregnancy care in the third trimester is yoga exercise. This study was to determine the effectiveness of prenatal yoga in reducing physical discomfort in the third trimester of pregnancy. This was a Quasi-Experimental study with NonEquivalent Control Group approach. The sample of this study were 32 pregnant women of the third trimester consisting of 16 people as intervention group and 16 people as control taken by consecutive sampling technique. Univariate analysis was performed frequency distribution, Wilcoxon test, and Mann Whitney test. The result showed that the mean difference between pretest and post-test of the control group was $-0.25 ;(p=0.417>\alpha=0.05)$. The difference of mean value between pre-test and post-test of the intervention group was 3.5; $(p=0,000<\alpha=0.05)$. The difference of the mean value of physical discomfort in control and intervention group was 3.75; $(p=0.000<\alpha=0,05)$, it means that there was a significant difference of the mean value of physical discomfort of respondent between control and intervention group. It can be concluded that prenatal yoga has effective to reduce the physical discomfort of a pregnant mother in the third trimester. This study suggests prenatal yoga program could implement in midwifery care especially in the class of pregnant women in Public health center routinely so that the discomfort of pregnant women during pregnancy can be overcome.
\end{abstract}

Keywords: Physical discomfort, Prenatal yoga

\begin{abstract}
Abstrak: Efektifitas Prenatal Yoga terhadap Pengurangan Keluhan Fisik pada Ibu Hamil Trimester III. Selama masa kehamilan ibu hamil mengalami perubahan fisik dan psikologis yang dapat menimbulkan ketidaknyamanan. Salah satu perawatan kehamilan pada trimester III adalah olahraga berupa yoga. Tujuan penelitian ini untuk mengetahui efektifitas prenatal yoga terhadap pengurangan keluhan fisik ibu hamil trimester III. Jenis penelitian Quasi Eksperimen pendekatan Non Equivalent Control Group. Sampel penelitian sebanyak 32 ibu hamil trimester III terdiri dari 16 orang sebagai kelompok intervensi dan 16 orang sebagai kontrol diambil dengan teknik consecutive sampling. Analisis univariat dilakukan distribusi frekuensi, uji Wilcoxon dan uji Mann Whitney. Hasil didapatkan nilai mean perbedaan antara pengukuran pre-test dan post-test kelompok kontrol sebesar $-0,25 ;(p=0,417>\alpha=0,05)$. Hasil perbedaan nilai mean antara pengukuran pre-test dan post-test kelompok intervensi sebesar 3.5; $(p=0,000<\alpha=0,05)$. Dan hasil perbedaan selisih nilai rata-rata keluhan fisik kelompok kontrol dan kelompok intervensi sebesar 3.75; $(p=0.000<\alpha=0,05$, hasil ini terdapat perbedaan signifikan nilai rata-rata keluhan fisik responden antara kelompok kontrol dan kelompok intervensi. Simpulan penelitian bahwa prenatal yoga efektif terhadap pengurangan keluhan fisik ibu hamil trimester III. Saran perlunya program prenatal yoga ini dilaksanakan dalam asuhan kebidanan khususnya pada kelas ibu hamil di Wilayah Kerja Puskesmas Kamonji secara rutin sehingga ketidakyamanan ibu hamil selama kehamilan dapat teratasi.
\end{abstract}

Kata kunci: Keluhan fisik, Prenatal yoga

Kehamilan yang mempunyai peluang lebih tinggi terkena komplikasi yang sering disebut sebagai kehamilan berisiko tinggi (Beers et al, 2003). Meskipun ada banyak komplikasi yang dapat terjadi selama kehamilan, gangguan hipertensi kehamilan (Gifford et al, 2000)dan kelahiran prematur (Lawn et al, 2005) adalah beberapa gangguan yang lebih umum. Stres oksidatif terjadi pada kesehatan ibu (Hsieh et al, 2012; Lappas et al, 2011) dan stres psikologis (Roy-Matton et al, 2011). 
Selama masa kehamilan ibu hamil mengalami perubahan fisik dan psikologis yang dapat menimbulkan ketidak-nyamanan terutama trimester II dan III seperti dispnea, insomnia, gingiviris dan epulsi, sering buang air kecil, tekanan dan ketidaknyamanan pada perineum, nyeri punggung, konstipasi, varises, mudah lelah, kontraksi Braxton hicks, kram kaki, edema pergelangan kaki (non pitting) dan perubahan mood serta peningkatan kecemasan (Bobak, 2005; Perry, et al., 2013).

Pemeliharaan kesehatan ibu hamil perlu dilakukan perawatan kehamilan. Penelitian yang dilakukan oleh Herawati (2006), diketahui bahwa ada hubungan bermakna antara upaya perawatan kehamilan dengan kejadian persalinan lama $(p=0,036)$ dengan OR sebesar 3,5965. Salah satu perawatan kehamilan pada trimester III adalah olahraga. Ternyata, bagi ibu hamil, olahraga juga mempunyai banyak manfaat. Olahraga dapat membantu dalam perubahan metabolisme tubuh selama kehamilan berdampak pada tingginya konsumsi oksigen pada tubuh, aliran darah jantung, volume dan curah jantung. Hal ini mengakibatkan perubahan peran jantung selama kehamilan yang berguna untuk membantu fungsi jantung, sehingga ibu hamil akan merasa lebih sehat dan tidak merasa sesak nafas. Prasetyono (2010) menambahkan manfaat lain yaitu dapat mengurangi berat dan frekuensi nyeri punggung akibat kehamilan dengan cara membantu mempertahankan postur tubuh yang lebih baik.

Ada beberapa cara tindakan pencegahan selama kehamilan agar ibu dan janin berada dalam kondisi sehat dan nantinya terjadi proses persalinan normal yaitu olahraga jalan pagi, bersepeda statis, aerobic, senam air, menari, dan yoga. Senam hamil memiliki beberapa metode latihan diantaranya yaitu yoga, pilates, kegel, hypnotherapy (Krisnadi, 2010).

Berusia lebih dari 5000 tahun, yoga adalah pendekatan holistik untuk fisik, mental, dan kesejahteraan spiritual yang berasal dari India (Bijlani, 2008). Ini melibatkan kombinasi dari peregangan, pernapasan, postur, dan bermeditasi yang mempromosikan kesehatan dan pertumbuhan rohani dalam praktisi (Chandler, 2001).

Prenatal yoga (yoga selama kehamilan) merupakan salah satu jenis modifikasi dari hatha yoga yang disesuaikan dengan kondisi ibu hamil. Tujuan prenatal yoga adalah mempersiapkan ibu hamil secara fisik, mental dan spiritual untuk proses persalinan. Dengan persiapan matang, sang ibu akan lebih percaya diri dan memperoleh keyakinan menjalani persalinan dengan lancar dan nyaman (Pratignyo, 2014).
Hasil studi pendahuluan yang dilakukan di Puskesmas Kamonji pada bulan Februari 2017 terdapat 5 ibu hamil trimester III mengalami keluhan sering buang air kecil, sulit tidur, sesak nafas dan sakit pinggang. Ditambah dengan kram kaki yang sering dirasakan pada malam hari. Hal tersebut menjadi keluhan fisiologi pada ibu hamil, tetapi perlunya penanganan agar keluhan berkurang. Tujuan penelitian untuk mengetahui efektifitas prenatal yoga terhadap pengurangan keluhan fisik ibu hamil trimester III. Penelitian ini bermanfaat dalam peningkatan pelayanan kesehatan khususnya para tenaga kesehatan di puskesmas Kamonji.

\section{METODE}

Jenis penelitian Quasi Experiment dengan menggunakan pendekatan Non Equivalent Control Group. Penelitian ini dilaksanakan bulan April 2017 di wilayah kerja Puskesmas Kamonji Kota Palu. Sampel penelitian 32 ibu hamil trimester III terdiri dari 16 orang sebagai kelompok intervensi dan 16 orang sebagai kontrol yang diambil menggunakan teknik consecutive sampling. Alat ukur berupa lembar kuisioner dengan wawancara sebelum (pre-test) mengenai keluhan fisik yang dialami ibu hamil trimester III baik kelompok intervensi maupun kelompok kontrol. Prenatal yoga pada kehamilan trimester III pada kelompok Intervensi, yang dilakukan mulai gerakan pemanasan (pemanasan leher, peregangan dan pemuntiran samping tubuh, peregangan bahu dan pundak) dilanjutkan gerakan Yoga: postur restorative (mudhasana/postur anak), postur berdiri (utkatasana/postur kursi, seri memutar panggul (pelvic rocking), postur melentur dan menguatkan panggul (seri postur berjongkok, baddha konasana/seri postur kupu-kupu), putaran sufi, meditasi sambil relaksasi pernafasan diafragma (Sindhu, 2014). Prenatal yoga dilakukan waktu latihan diberikan selama 30-60 menit ke seluruhan gerakan. Setelah pelaksanaan yoga, kemudian sesudah (post-test) diukur keluhan ibu hamil. Pada kelompok kontrol dilakukan pengkajian keluhan fisik ibu hamil trimester III pre-test dan post-test tanpa intervensi. Analisis univariat dilakukan distribusi frekuensi dan uji Wilcoxon dan uji Mann Whitney dengan $\alpha=0,05$ dan CI95\%. 
HASIL

\section{A. ANALISIS UNIVARIAT}

Tabel 1.Distribusi Karakteristik Responden

\begin{tabular}{lcc}
\hline Karakteristik & Frekuensi & \% \\
\hline Pendidikan & & \\
Tinggi & 11 & 34,4 \\
Rendah & 21 & 65,6 \\
\hline Pekerjaan & & \\
Tidak bekerja & 20 & 62,5 \\
Bekerja & 12 & 12,5 \\
\hline Jumlah & $\mathbf{3 2}$ & $\mathbf{1 0 0}$ \\
\hline
\end{tabular}

Tabel 1 menunjukkan responden berpendidikan terbanyak adalah pendidikan rendah sebanyak 21 responden $(56,25 \%)$ dan pekerjaan responden terbanyak adalah tidak bekerja 20 responden $(62,5 \%)$.

\section{Tabel 2. Distribusi Keluhan Fisik Responden Pre-test Post-test Kelompok Intervensi}

\begin{tabular}{lrrrr}
\hline \multirow{2}{*}{\multicolumn{1}{c}{ Keluhan Fisik }} & \multicolumn{1}{c}{ Pre-test } & \multicolumn{2}{c}{ Post-test } \\
\cline { 2 - 5 } & \multicolumn{1}{c}{$\boldsymbol{f}$} & \multicolumn{1}{c}{$\boldsymbol{~} \boldsymbol{f}$} & \multicolumn{1}{c}{$\%$} \\
\hline Sering Buang Air Kecil & 15 & 93.75 & 15 & 93.75 \\
Konstipasi/sembelit & 10 & 62.5 & 6 & 37.5 \\
Kram pada kaki & 5 & 31.25 & 3 & 18.75 \\
Pusing & 4 & 25 & 2 & 12.5 \\
Perut Kembung & 11 & 68.75 & 1 & 6.25 \\
Bengkak pada kaki & 7 & 43.75 & 7 & 43.75 \\
Susah tidur & 15 & 93.75 & 10 & 62.5 \\
Kesemutan pada jari & & & & \\
tangan dan kaki & 14 & 87.5 & 4 & 25 \\
Sesak nafas & 15 & 93.75 & 4 & 25 \\
Spasme Otot & 9 & 56.25 & 1 & 6.25 \\
Nyeri pinggang atas dan & & & & \\
bawah & 16 & 100 & 12 & 75 \\
\hline
\end{tabular}

Tabel 2 menunjukkan dari 11 keluhan yang menjadi indikator penilaian, diantaranya responden yang merasakan pengurangan keluhan fisik paling banyak setelah prenatal yoga adalah spasme otot, perut kembung, kesemutan pada jari tangan dan kaki, sesak nafas. Sedangkan keluhan yang masih tetap sering buang air kecil dan bengkak pada kaki.

Tabel 3. Nilai Keluhan Fisik Pre-test Post-test Kelompok Kontrol

\begin{tabular}{crrcc}
\hline $\begin{array}{c}\text { Nilai } \\
\text { Keluhan }\end{array}$ & $\begin{array}{c}\text { Mean } \\
\text { Median }\end{array}$ & SD & $\begin{array}{c}\text { Min- } \\
\text { Mak }\end{array}$ & $\begin{array}{c}\text { 95\% } \\
\text { CI }\end{array}$ \\
\hline Pre-test & 5.56 & 1.09 & $3-7$ & $4.97-6.14$ \\
& 6 & & & \\
Post-test & 5.81 & 0.65 & $5-7$ & $5.46-6.16$ \\
& 6 & & & \\
\hline
\end{tabular}

Pada tabel 3 hasil statistik bahwa nilai ratarata keluhan fisik responden pada pengukuran pre-test kelompok kontrol diperoleh 5.56 dengan standar deviasi 1.09. Sedangkan nilai rata-rata keluhan fisik responden pada pengukuran posttest kelompok control sebesar 5.81 dan standar deviasi 0.65 .

Tabel 4. Nilai Keluhan Fisik Pretest Posttest Kelompok Intervensi

\begin{tabular}{crrrc}
\hline $\begin{array}{c}\text { Nilai } \\
\text { Keluhan }\end{array}$ & $\begin{array}{c}\text { Mean } \\
\text { Median }\end{array}$ & SD & $\begin{array}{c}\text { Min- } \\
\text { Mak }\end{array}$ & $\begin{array}{c}\text { 95\% } \\
\text { CI }\end{array}$ \\
\hline Pre-test & 7.56 & 1.03 & $5-9$ & $7.01-8.11$ \\
& 8 & & & \\
Posttest & 4.06 & 1.06 & $2-6$ & $3.49-4.62$ \\
& 4 & & & \\
\hline
\end{tabular}

Tabel 4 menunjukkan hasil statistik bahwa nilai rata-rata keluhan fisik responden pada pengukuran sebelum dilakukan prenatal yoga diperoleh 7.56 dengan standar deviasi 1.03. Sedangkan nilai rata-rata keluhan fisik responden pada pengukuran sesudah dilakukan prenatal yoga kelompok intervensi sebesar 4.06 dan standar deviasi 1.06

\section{B. ANALISIS BIVARIAT}

Untuk melihat perbedaan keluhan fisik pretest-posttest kelompok kontrol dan kelompok intervensi.

Tabel 5. Perbedaan KeluhanFisik Pre-test Post-test Kelompok Kontrol

\begin{tabular}{lccccc}
\hline $\begin{array}{c}\text { Nilai } \\
\text { Keluhan }\end{array}$ & $\mathbf{n}$ & Mean & SD & $\mathbf{Z}$ & $\boldsymbol{p}$ \\
\hline $\begin{array}{l}\text { Pretest } \\
\text { dan }\end{array}$ & 32 & 5.56 & 1.09 & & \\
$\begin{array}{l}\text { Posttest } \\
\text { Pan }\end{array}$ & & 5.81 & 0.65 & & 0.417 \\
\hline
\end{tabular}

Tabel 5 terlihat nilai mean perbedaan antara pengukuran pretest dan posttest kelompok kontrol sebesar -0,25. Hasil uji Wilcoxon diperoleh nilai $p=0,417$, maka nilai $p=0,417>\alpha=0,05$, maka dapat disimpulkan tidak ada perbedaan yang signifikan antara keluhan ibu hamil pada pengukuran sebelum dan sesudah pada ibu hamil trimester III.

Tabel 6. Perbedaan Keluhan Fisik PretestPosttest Kelompok Intervensi

\begin{tabular}{lcrlll}
$\begin{array}{l}\text { Nilai } \\
\text { Keluhan }\end{array}$ & $\mathbf{n}$ & Mean & SD & Z & p \\
$\begin{array}{l}\text { Pre-test } \\
\text { dan }\end{array}$ & 32 & 7.56 & 1.03 & & \\
$\begin{array}{l}\text { Post-test } \\
\text { Post }\end{array}$ & 4.06 & 1.06 & & \\
\hline
\end{tabular}

Tabel 6 menunjukkan perbedaan nilai mean antara pengukuran pre-test dan post-test kelompok intervensi sebesar 3.5. Hasil uji 
Wilcoxon diperoleh nilai $p=0.000$, maka nilai $p=0,000>\alpha=0,05$, maka dapat disimpulkan ada perbedaan yang signifikan antara keluhan ibu hamil sebelum dilakukan prenatal yoga dan setelah dilakukan prenatal yoga.

\begin{tabular}{|c|c|c|c|c|}
\hline $\begin{array}{r}\text { Tabel 7. Pe } \\
\text { Po } \\
\text { Ke }\end{array}$ & $\begin{array}{l}\text { eda } \\
\text { test } \\
\text { mpc }\end{array}$ & $\begin{array}{r}\text { Keluhan } \\
\text { Kelompok } \\
\text { Intervensi }\end{array}$ & $\begin{array}{l}\text { Fisil } \\
\text { kon }\end{array}$ & Pre \\
\hline Kelompok & n & $\begin{array}{l}\text { Selisih } \\
\text { Mean }\end{array}$ & $\mathbf{Z}$ & $p$ \\
\hline $\begin{array}{l}\text { Kontrol } \\
\text { Intervensi }\end{array}$ & 32 & 3.75 & -4.05 & 0,000 \\
\hline
\end{tabular}

Pada tabel 7 diperoleh perbedaan selisih nilai rata-rata keluhan fisik kelompok kontrol dan kelompok intervensi sebesar 3.75. Hasil uji statistik Mann Whitney didapatkan nilai nilai $p=0.000 \quad(p<0.05)$. Hal ini dapat disimpulkan adanya perbedaan signifikan nilai mean keluhan fisik responden antara kelompok kontrol dan kelompok intervensi.

\section{PEMBAHASAN}

Berdasarkan hasil penelitian, pendidikan rendah (SD, SMP, SMA) yang lebih banyak, hal ini yang mendasari responden masih belum mengetahui tentang prenatal yoga karena sebelumnya tidak terpapar informasi yang diberikan dari pelayanan kesehatan terutama kelas prenatal, walaupun sebagian responden ada pula yang mengetahui dari sosial media seperti responden yang pendidikan tinggi.

Responden yang tidak bekerja di luar rumah yang terbanyak yaitu IRT. Hal ini pula yang menjadi beban bertambahnya keluhan fisik ibu karena banyaknya beban pekerjaan yang dilakukan di rumah, sedangkan kondisi tubuhnya semakin berat dan ditambah gerakan posisi tubuh saat bekerja yang tidak tepat dengan baik serta waktu untuk merawat dirinya terbatas seperti berolahraga.

Berdasarkan hasil penelitian, semua responden merasakan 11 keluhan fisik sebelum prenatal yoga dan responden mengalami pengurangan keluhan fisik setelah dilakukan prenatal yoga diantaranya spasme otot, perut kembung, kesemutan pada jari tangan dan kaki, sesak nafas, pusing, kram pada kaki, konstipasi/sembelit, susah tidur dan nyeri punggung atas dan bawah.

Terjadinya perubahan keluhan fisik tersebut setelah latihan prenatal yoga, hal ini dikarenakan tubuh mengalami peregangan otot lebih rileks, sehingga peredaran darah bekerja dengan baik dan tubuh memproduksi hormon Endorphin. Menurut Widiastini (2016) bahwa Endorphin adalah hormon yang alami yang diproduksi oleh tubuh manusia, maka endorphin adalah penghilang rasa sakit yang terbaik. Endorphin dapat diproduksi secara alami dengan cara melakukan aktivitas seperti meditasi, melakukan pernafasan dalam, makan makanan yang pedas, atau melalui acupuncture treatments atau chiropractic.

Hasil penelitian ini sesuai dengan teori Sindhu (2014), bahwa dengan berlatih yoga pada masa kehamilan merupakan salah satu solusi yang bermanfaat sebagai media self help yang akan mengurangi ketidaknyamanan selama masa hamil, membantu proses persalinan, dan bahkan mempersiapkan mental untuk masa-masa awal setelah melahirkan dan saat membesarkan anak. Ibu hamil yang berolahraga secara teratur, tingkat laporan mengalami ketidaknyamanan selama kehamilan lebih rendah dan penyembuhan lebih cepat daripada yang tidak berolahraga selama kehamilan.

Penelitian ini sependapat dengan teori dan hasil penelitian yang dikemukakan oleh Stoppard (2008); Beddoe (2008); Sindhu (2009) dan Wiadnyana (2011) bahwa manfaat latihan yoga bagi ibu hamil, bersalin dan nifas yaitu dapat meringankan edema dan kram yang sering terjadi pada bulan-bulan terakhir kehamilan, membantu posisi bayi dan pergerakan, meningkatkan sistem pencernaan dan nafsu makan, meningkatkan energi dan memperlambat metabolisme untuk memulihkan ketenangan dan fokus, mengurangi rasa mual, morning sickness dan suasana hati, meredakan ketegangan di sekitar leher rahim dan jalan lahir, yang berfokus pada membuka pelvis untuk mempermudah persalinan, membantu dalam perawatan pasca kelahiran dengan mengembalikan uterus, perut dan dasar panggul, mengurangi ketegangan, cemas dan depresi selama hamil, persalinan nifas dan ketidaknyamanan payudara.

Penelitian ini sejalan dengan penelitian yang dilakukan oleh Mediarti (2014) bahwa ratarata keluhan ibu hamil pada pengukuran sebelum dilakukan yoga antenatal adalah 12,78 dengan standar deviasi 2,210. Pada pengukuran setelah dilakukan yoga antenatal didapatkan rata-rata keluhan ibu hamil 12,19 dengan standar deviasi 2,912. Terlihat nilai mean perbedaan antara pengukuran pre-test dan post-test adalah 0,59 dengan standar deviasi 1,103. Hasil uji statistik didapatkan nilai $p=0,005$ maka dapat disimpulkan ada perbedaan yang signifikan antara keluhan ibu hamil sebelum dilakukan yoga antenatal dan setelah dilakukan yoga antenatal. 
Menurut Sun, et.al, (2010) penelitian mengungkapkan program yoga dapat menurunkan ketidakyamanan perempuan selama kehamilan dan meningkatkan kepercayaan dalam proses persalinan. Penelitian menyarankan penggunaan sebagai salah faktor dalam mempromosikan kesehatan wanita untuk menjadi lebih sehat dan mengurangi ketidaknyaman sering timbul dalam kehamilan.

Menurut Mediarti, dkk. (2014), yoga yang dilakukan oleh ibu hamil secara teratur ternyata banyak manfaatnya bagi ibu dan janin. Diantaranya meningkatkan berat badan bayi saat dilahirkan, mengurangi terjadinya kelahiran prematur dan berbagai komplikasi kehamilan. Latihan yoga yang dilakukan diantaranya mencakup berbagai relaksasi, mengatur postur (yoga asana), olah napas dan meditasi selama satu jam, rutin setiap hari. Hasilnya, 14\% kelompok rajin yoga yang melahirkan bayi prematur, sementara kelompok yang tidak beryoga $20 \%$. Selain itu kelompok beryoga juga lebih rendah tekanan darahnya.

Menurut Sun, et al., (2010), yoga juga mengurangi rasa dan menghilangkan beberapa ketidaknyamanan dalam kehamilan, meningkatkan kekuatan otot yang khususnya sangat bermanfaat dalam mencegah back pain, dapat membantu wanita merasa lebih lincah dan gesit, serta keseimbangan perubahan berat badan dan memfasilitasi perubahan gaya gravitasi saat kehamilan. Latihan yoga dalam penelitian ini tidak hanya menguatkan kelompok otot-otot bahu, belakang dan kaki. Tetapi juga membantu memperoleh posisi tubuh yang benar, dimana hal-hal tersebut dapat mengurangi nyeri punggung pada wanita hamil.

Chuntharapat, et al., (2010), selama kehamilan wanita mengalami banyak ketidaknyamanan yang mungkin saja bukan merupakan sebuah symptom yang terisolasi, tetapi semua masalah yang terintegrasi dan salah satu keluhan dapat memperparah keluhan lain. Penelitian terbaru mengindikasikan bahwa wanita hamil dengan tingkat stres dan kegelisahan yang tinggi memiliki risiko melahirkan janin yang tidak sehat. Selama wanita hamil mengalami stres seluruh sistem regulasi stres teraktivasi yang menyebabkan berbagai hormon seperti Kortikotropin Relasing Hormone, Adenocotikotropin Relaxing Hormone, Kortisol dan nor adrenalin dilepaskan pada sirkulasi darah, wanita hamil memiliki respon yang berbeda-beda terhadap stimulus stres tersebut tergantung pada pengalaman sebelumnya, faktor genetik, dukungan social atau kepribadian. Yoga adalah salah satu solusi dari sekian banyak alternatif yang baik dalam meningkatkan kenyamanan ibu selama kehamilan pergerakkan yang tersinkronisasi pada Senam hamil Yoga pada kelompok intevensi skor kenyamanan secara konsisten lebih tinggi daripada kelompok kontrol. Ibu hamil pada kelompok intervensi memiliki skor kenyamanan 3 kali lebih nyaman berdasarkan lembar observasi kenyamanan maternal dan 6 kali lebih nyaman berdasarkan analog visual scale, walaupun ibu hamil pada kelompok kontrol juga mengalami penurunan kenyamanan yang alamiah selama kehamilan.

Seluruh aspek praktek yoga membawa ibu pada keadaan relaksasi yang dalam dimana ibu merasakan kenyamanan di dalam tubuh dan pikirannya. Yoga dapat membantu wanita hamil dengan memberikannya alat yang dibutuhannya untuk menjalani kehamilan yang nyaman (Chuntharapat, et.al. 2008).

Responden dengan keluhan tidak mengalami pengurangan yaitu sering buang air kecil dan bengkak pada kaki. Hal ini karena penelitian ini hanya dilakukan sekali intervensi latihan yoga, sehingga pengurangan keluhan fisik tidak semua terjadi. Berbeda dengan hasil penelitian yang dilakukan Pont dan Longulo (2017) menunjukkan dari semua 34 responden yang merasakan 16 keluhan sebelum senam hamil yoga dan setelah responden mengalami pengurangan semua keluhan diantaranya merasa cepat lelah, sukar tidur, nafas pendek, kaki tangan oedema, nyeri pinggang, spasme otot, cemas, rasa sakit perut bagian bawah, merasa panas ada gerah, sering buang air kecil, kaki kram, kontraksi palsu, varices, wasir, stretch march dan konstipasi. Keluhan yang paling banyak dirasakan responden keluhan yang tidak dirasakan setelah senam hamil yoga adalah spasme otot sebesar $0 \%$.

Hasil penelitian ini didukung pula dengan pendapat Nugroho, dkk (2014). Dimana pembesaran ureter kiri dan kanan dipengaruhi oleh horman progesteron, tetapi kanan lebih membesar karena uterus lebih sering memutar ke kanan (hidroureter dextra) dan pielitis detra lebih sering. Poliuria karena peningkatan filtrasi glomerulus. Trimester I kehamilan kandung kemih tertekan uterus yang mulai membesar, akibatnya ibu sering kencing. Trimester II kehamilan dimana uterus telah keluar dari rongga pelvis gejala sering kecing tidak di jumpai lagi. Trimester III, bila kepala janin mulai turun ke PAP, keluhan sering kencing timbul lagi karena kandung kemih tertekan.

Menurut Mediarti (2014), pada ibu hamil terjadi perubahan fisiologis yang tidak hanya berhubungan dengan bentuk dan berat badan, 
tetapi juga perubahan biokimia, fisiologis, bahkan emosional yang merupakan konsekuensi dari pertumbuhan janin dalam rahim. Sejalan dengan pertumbuhan janin dan mendorong diafragma ke atas, bentuk dan ukuran rongga dada berubah tetapi tidak membuatnya lebih kecil. Kapasitas paru terhadap udara inspirasi tetap sama seperti sebelum hamil atau mungkin berubah dengan berarti. Kecepatan pernapasan dan kapasitas vital tidak berubah. Volume tidal, volume ventilator permenit, dan ambilan oksigen meningkat. Karena bentuk dari rongga torak berubah dan karena bernapas lebih cepat, sekitar $60 \%$ wanita hamil mengeluh sesak nafas.

Pada wanita hamil terjadi perubahanperubahan yang sangat spesifik, yaitu perubahan pada sistem reproduksi, sistem intergumen, sistem endokrin, sistem kardiovaskuler, sistem muskuloskuletal, sistem pernapasan, sistem gastrointestinal (pencernaan), dan sistem perkemihan. Perubahan ini merupakan hal yang wajar dan normal yang tidak perlu ditakuti. Perubahan-perubahan yang terjadi selama kehamilan akan kembali seperti keadaan sebelum

\section{DAFTAR PUSTAKA}

Beddoe, A. E., \& Lee, K. A. 2008. Mind-body interventions during pregnancy. Journal of Obstetric, Gynecologic, \& Neonatal Nursing, 37(2), 165-175. http://jognn.awhonn.org

Beers, M.H., Fletcher, A.J., Jones, T.V., Porter, R. 2003. The Merck Manual of Medical Information. Simon \& Schuster, Inc., New York, NY.

Bijlani, R. 2008. Yoga: An Ancient Tool in Modern Medicine. The National medical journal of India.

Bobak, I.M., Lowdermilk, D. \& Jensen, M.D. 2005. Keperawatan maternitas. Alih bahasa.Wijayarini, M.A. \& Anugerah, P.I. Edisi 4. Jakarta: EGC.

Chandler, K. 2001. The Emerging Field Of Yoga Therapy. Hawaii Med. J. 60, 286-287.

Chuntharapat S, Petpichetchian W, Hatthakit U. 2010. Effect Of A Yoga Programme On Maternal Comfort During Pregnancy. Songkla Med J. Vol. 26 No. 2 Mar-Apr. Prince of Songkla University. 2008. Yoga During Pregnancy: Effects On Maternal Comfort, Labor Pain And Birth Outcomees. Complementary Therapies in Clinical Practice 14, 105115. hamil, setelah proses persalinan dan menyusui selesai (Romauli, 2011).

\section{SIMPULAN}

Keluhan fisik yang berkurang setelah prenatal yoga diantaranya spasme otot, perut kembung, kesemutan pada jari tangan dan kaki, sesak nafas, pusing, kram pada kaki, konstipasi/sembelit, susah tidur, nyeri punggung atas dan bawah. Prenatal yoga efektif terhadap pengurangan keluhan fisik ibu hamil trimester III di Wilayah Kerja Puskesmas Kamonji.

\section{SARAN}

Perlunya program prenatal yoga ini dilaksanakan dalam asuhan kebidanan khususnya pada kelas ibu hamil di Wilayah Kerja Puskesmas Kamonji secara rutin sehingga ketidaknyamanan ibu hamil selama kehamilan dapat teratasi.

Gifford, R. W. A. P. 2000. Report of the national high blood pressure education program working group on high blood pressure in pregnancy. Am J Obstet Gynecol, 183, S1S15.

Herawati, B. 2006. Hubungan Kondisi Fisik Dan Upaya Perawatan Kehamilan dengan Kejadian Persalinan Lama di Kabupaten Bengkulu Selatan Tahun 2005. [Disertasi]. Semarang: Universitas Diponegoro. http://www.fkm.undip.ac.id.

Hsieh, T., Chen, S., Lo, L., Li, M., Yeh, Y., Hung, T.2012. The Association Between Maternal Oxidative Stress At MidGestation And Subsequent Pregnancy Complications. Reprod. Sci. 19, 505-512.

Krisnadi, Sofie Rifayani. 2010. Sinopsis Yoga Untuk Kehamilan: Sehat, Bahagia Dan Penuh Makna. http://www.bukukita.com. Jakarta.

Lappas, M., Hiden, U., Desoye, G., Froehlich, J., Mouzon, S. H. D., \& Jawerbaum, A. 2011. The role of oxidative stress in the pathophysiology of gestational diabetes mellitus. Antioxidants \& redox signaling, 15(12), 3061-3100.

Lawn, J. E., Cousens, S., Zupan, J., \& Lancet Neonatal Survival Steering Team. 2005. 4 
million neonatal deaths: when? Where? Why?. The lancet, 365(9462), 891-900.

Mediarti, D., Sulaiman, S., Rosnani, R., \& Jawiah, J. 2014. Pengaruh Yoga Antenatal Terhadap Pengurangan Keluhan Ibu Hamil Trimester III. Jurnal Kedokteran \& Kesehatan: Publikasi Ilmiah Fakultas Kedokteran Universitas Sriwijaya, 1(1), 47-53.

Nugroho T, Nurrezki, Warnaliza D, dan Wilis. 2014. Buku Ajaran Asuhan Kebidanan I (Kehamilan). Yogyakarta: Nuha Medika.

Pont A.V dan Longulo O.J. 2017. Efektifitas Senam Hamil Yoga dalam Mengurangi Keluhan Ibu Hamil Saat Trimester III di Kota Palu. [Naskah Laporan Penelitan]. Politeknik Kesehatan Kemenkes Palu.

Prasetyono. 2010. Buku Panduan Lengkap Bagi Wanita Yang Sulit Hamil, Tips Bisa Cepat Hamil. Yogyakarta: Gara Ilmu.

Pratignyo T. 2014. Yoga Ibu Hamil Plus: Postnatal Yogal. Jakarta: Pustaka Bunda.

Perry, S. E., Hockenberry, M. J., Lowdermilk, D. L., \& Wilson, D. 2013. Maternal child nursing care. Elsevier Health Sciences.

Romauli, S. 2011. Asuhan Kebidanan 1 Konsep Dasar Asuhan Kehamilan. Yogyakarta: Nuha Medika.
Roy-Matton, N., Moutquin, J., Brown, C., Carrier, N., Bell, L. 2011. The Impact Of Perceived Maternal Stress And Other Psychosocial Risk Factors On Pregnancy Complications. J. Obstet. Gynaecol. Can. 33, 344-352.

Sindhu P. 2009. Yoga untuk kehamilan sehat, bahagia dan penuh makna.Seri bugar. Bandung: Qonita, Mizan Pustaka. - 2014. Yoga Untuk Kehamilan Sehat, Bahagia, \& Penuh Makna. Edisi yang Diperkaya. Bandung: Qanita.

Stoppard, M. 2008. Conception Pregnancy And Birth: Ensiklopedia Kehamilan. Surabaya: Erlangga.

Sun, Y. C., Hung, Y. C., Chang, Y., \& Kuo, S. C. 2010. Effects of a prenatal yoga programme on the discomforts of pregnancy and maternal childbirth selfefficacy in Taiwan. Midwifery, 26(6), e31e36.

Wiadnyana, M.S. 2011. The Power Of Yoga For Pregnancy And Post-Pregnancy. Jakarta: PT. Gramedia Pustaka Utama.

Widiastini, L. P. 2016. Pengaruh Massage Endorphin Terhadap Kecemasan Ibu Hamil Dalam Menghadapi Proses Persalinan Di Puskesmas Denpasar Utara III. Jurnal Dunia Kesehatan, 5(2). 